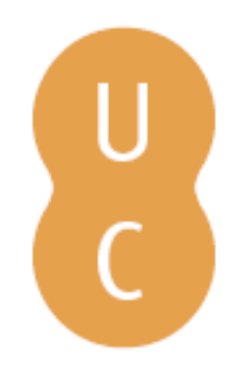

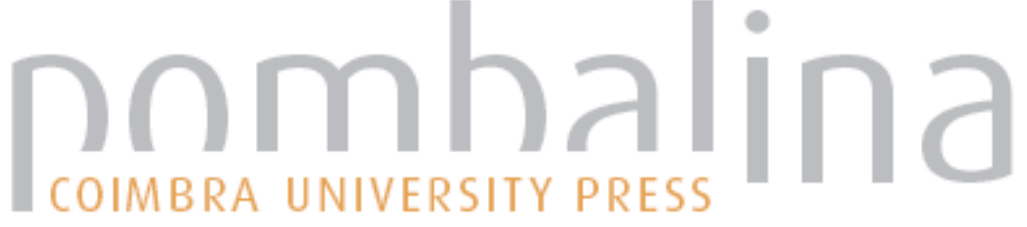

Do we need weather prediction models to account for local weather modifications by wildland fires?
Autor(es):
Kochanski, Adam; Mallia, Derek V.; Fearon, Matthew G.; Brown, Tim; Mandel, Jan; Vaughan, Joseph K.

Publicado por: Imprensa da Universidade de Coimbra

URL persistente:

URI:http://hdl.handle.net/10316.2/44625

DOI:

DOI:https://doi.org/10.14195/978-989-26-16-506_108

Accessed : $\quad$ 26-Apr-2023 13:25:22

A navegação consulta e descarregamento dos títulos inseridos nas Bibliotecas Digitais UC Digitalis, UC Pombalina e UC Impactum, pressupõem a aceitação plena e sem reservas dos Termos e Condições de Uso destas Bibliotecas Digitais, disponíveis em https://digitalis.uc.pt/pt-pt/termos.

Conforme exposto nos referidos Termos e Condições de Uso, o descarregamento de títulos de acesso restrito requer uma licença válida de autorização devendo o utilizador aceder ao(s) documento(s) a partir de um endereço de IP da instituição detentora da supramencionada licença.

Ao utilizador é apenas permitido o descarregamento para uso pessoal, pelo que o emprego do(s) título(s) descarregado(s) para outro fim, designadamente comercial, carece de autorização do respetivo autor ou editor da obra.

Na medida em que todas as obras da UC Digitalis se encontram protegidas pelo Código do Direito de Autor e Direitos Conexos e demais legislação aplicável, toda a cópia, parcial ou total, deste documento, nos casos em que é legalmente admitida, deverá conter ou fazer-se acompanhar por este aviso.

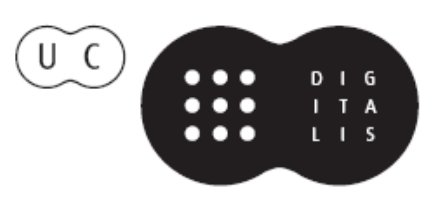




\section{ADVANCES IN}

\section{FOREST FIRE RESEARCH}

\section{8}

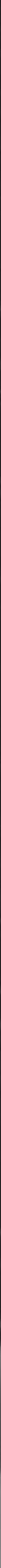




\title{
Do we need weather prediction models to account for local weather modifications by wildland fires?
}

\author{
Adam Kochanski ${ }^{1}$; Derek V. Mallia ${ }^{1}$, Matthew G. Fearon ${ }^{2}$, Tim Brown ${ }^{2}$, Jan Mandel $^{3}$, Joseph K. \\ Vaughan ${ }^{4}$ \\ ${ }^{1}$ University of Utah. Salt Lake City, Utah,USA. \{adam.kochanski@utah.edu*, \\ derek.mallia@utah.edu\} \\ ${ }^{2}$ Desert Research Institute, Reno, Nevada, USA. \{matthew.fearon@dri.edu,tim.brown@dri.edu\} \\ ${ }^{3}$ University of Colorado Denver, Denver, Colorado,USA. \{jan.mandel@ucdenver.edu\} \\ ${ }^{4}$ Washingon State University, Pullman,WA, USA. \{jvaughan@wsu.edu\}
}

\begin{abstract}
During the summer of 2015, a number of wildfires fires burned across northern California, which produced significant smoke across the region. Smoke from these wildfires hindered fire-fighting efforts by delaying helicopter operations and exposed communities to high concentrations of atmospheric pollutants. Nighttime inversions are common across the western U.S. and usually mix out during the early afternoon as a result of convective mixing from daytime heating. However, atmospheric conditions in valleys adjacent to the aforementioned wildfires remained stable throughout the afternoon. It is hypothesized that the smoke from nearby wildfires enhanced atmospheric stability due to surface cooling caused by reduced incoming solar radiation, and possibly by warming aloft due to absorption of the incoming solar radiation in the smoke layer. At the same time, mid-level heating from the wildfire could have increased atmospheric stability and extended the duration of the inversion.

In this study, we utilize the WRF-SFIRE-CHEM modeling framework, which couples an atmospheric, chemical, and fire spread model in an effort the model the impacts of smoke on local inversions and to improve the physical understanding behind these smoke-induced inversion episodes. This modeling framework was used to simulate the Route and South Complex fires between August 10 - August $26^{\text {th }}, 2015$. Preliminary results indicate that wildfire smoke may have significantly reduced incoming solar radiation, leading to local surface cooling by up to 2-3 degrees. Direct heating from the fire itself does not significantly enhance atmospheric stability. However, mid-level warming was observed in the smoke layer suggesting that absorption in this layer may have enhanced the inversion. This study suggests the including the fire-smokeatmosphere feedbacks in a coupled modeling framework such as WRF-SFIRE-CHEM may help in capturing the impacts of wildfire smoke on near-surface stability and local inversions.
\end{abstract}

Keywords: smoke, air quality, inversion

\section{Introduction}

It has long been recognized that weather can have large impacts on fire behavior and that sudden changes in winds at the fire line can have significant influences on fire behavior and other hazards (Albini 1982). Since wind at the fire line can impact fire spread and other fire phenomena such as plume rises, and smoke generation and transport, the prediction of the meteorology driving the fire must accurately account for all scales of motion ranging from synoptic-scale down to the fire line scale. This requirement is difficult to satisfy, as fire is dynamically coupled with the atmosphere. Recent studies by Clements et al. (2007), Lareau and Clements (2015), and Lareau and Clements 
(2017) provide observational evidence of fire-driven modifications of local weather, including the development of the pyro-convective plumes, in addition to the modification of local-scale winds that can extend several kilometers from the fire.

Weather data used to drive operational fire propagation models like BehavePlus (Andrews 2009) typically come from nearby weather stations or numerical weather forecasts. In order to refine relatively coarse resolution numerical weather prediction product and improve the accuracy of wind forecasts in complex terrain, diagnostic models such as WindNinja (Forthofer et al. 2014) are used to refine winds to finer scales. These models typically downscale wind forecasts at coarser resolutions ( 1-12 km in order to account for local terrain-induced circulations. However, downscaling is applied to the larger scale weather forecasting model, that does not account for the dynamical feedbacks between fire and the atmosphere. From that standpoint, it is important to assess if the local weather modifications due to the fire are significant enough to motivate coupling between the numerical weather prediction models, and the fire models.

Dynamical impacts of fire on the atmosphere exist at a variety of different scales ranging from meters to kilometers. Physically, fire-induced weather modifications may include:

1. modification of horizontal winds near the fire line as well as the vertical wind profile

2. formation of pyro-convective columns, and upper-level warming due to the condensation of water vapor in the smoke column

3. change of the atmospheric chemical composition due to the injection of smoke

4. atmospheric warming due to the heat release from the fire, and

5. radiative effects of smoke aerosols

In this paper, we focus on the last two aspects of fire-induced weather modifications, the direct warming due to the fire heat-release and the radiative impacts of smoke through atmospheric absorption and scattering.

\section{Motivation}

During the summer of 2015, a number of large wildfires burned across northern California in areas of localized topographic relief (Figure a). Persistent valley smoke hindered fire-fighting efforts, delayed helicopter operations, and exposed communities to high concentrations of atmospheric pollutants.

a)

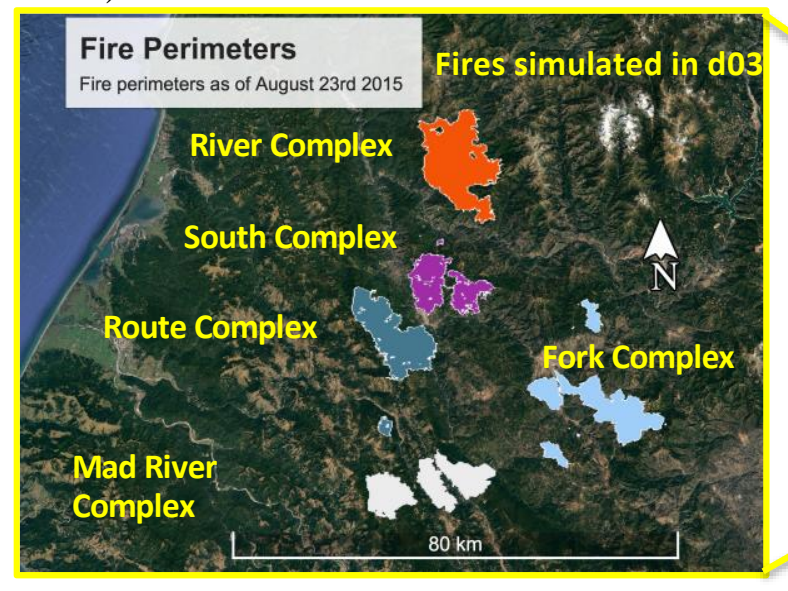

b)

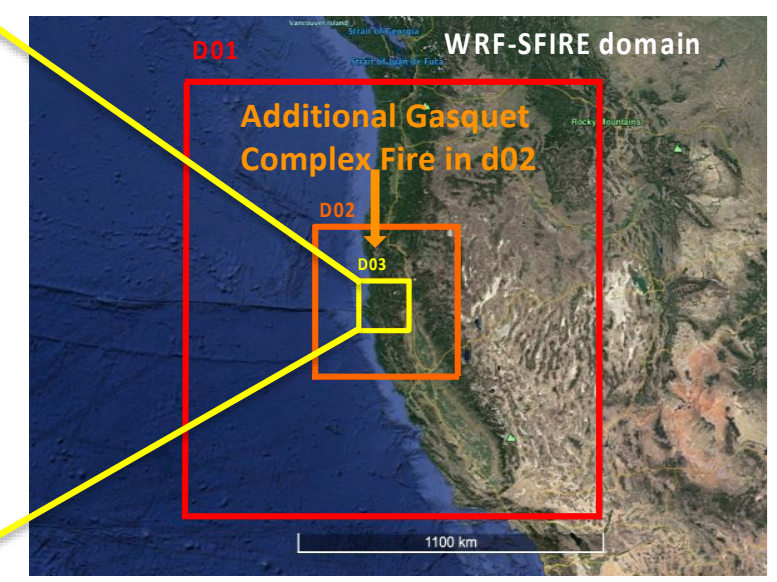

Figure 1 - Active fires across northern California on August $23^{r d}$, 2015 within the innermost domain d03 (a), and WRF-SFIRE-CHEM domain setup with the indication of the additional fire within domain d02 (b).

While nighttime inversion conditions are common in valleys across the West, the inversion during this event lasted longer than typical, as it persisted through the late afternoon. Pronounced cooling was 
observed in valleys across northern California, while upper-elevation locations above the smoke layer saw minimal decreases in surface temperatures. It was hypothesized that the combination of increased scattering and absorption within the smoke layer and mid-level atmospheric heating from the fire helped maintain a feedback process that extended the inversion period. This project utilized the coupled WRF-SFIRE-CHEM system to examine this hypothesis and to determine whether this modeling framework could be used to accurately forecast smoke-induced inversions in the future.

\section{Methodology}

Here we used WRF-SFIRE-CHEM, which is an extension of WRF-SFIRE modeling framework (Mandel et al. 2011). This model framework couples the SFIRE propagation model with a chemical transport model (WRF-CHEM; Grell et al. 2011). The integration of the atmospheric, fire and chemical transport models enables direct simulations of the fire propagation, plume rise, as well as smoke dispersion and chemical transformations (Kochanski et al. 2016). For the purpose of this study, the existing coupling between the fire and the chemistry model has been extended by implementing the Goddard Chemistry Aerosol Radiation and Transport (GOCART) scheme (Chin et al. 2000) to account for aerosol impacts on incoming solar radiation. A schematic diagram showing the coupling mechanisms between WRF-SFIRE-CHEM components is presented in Figure .

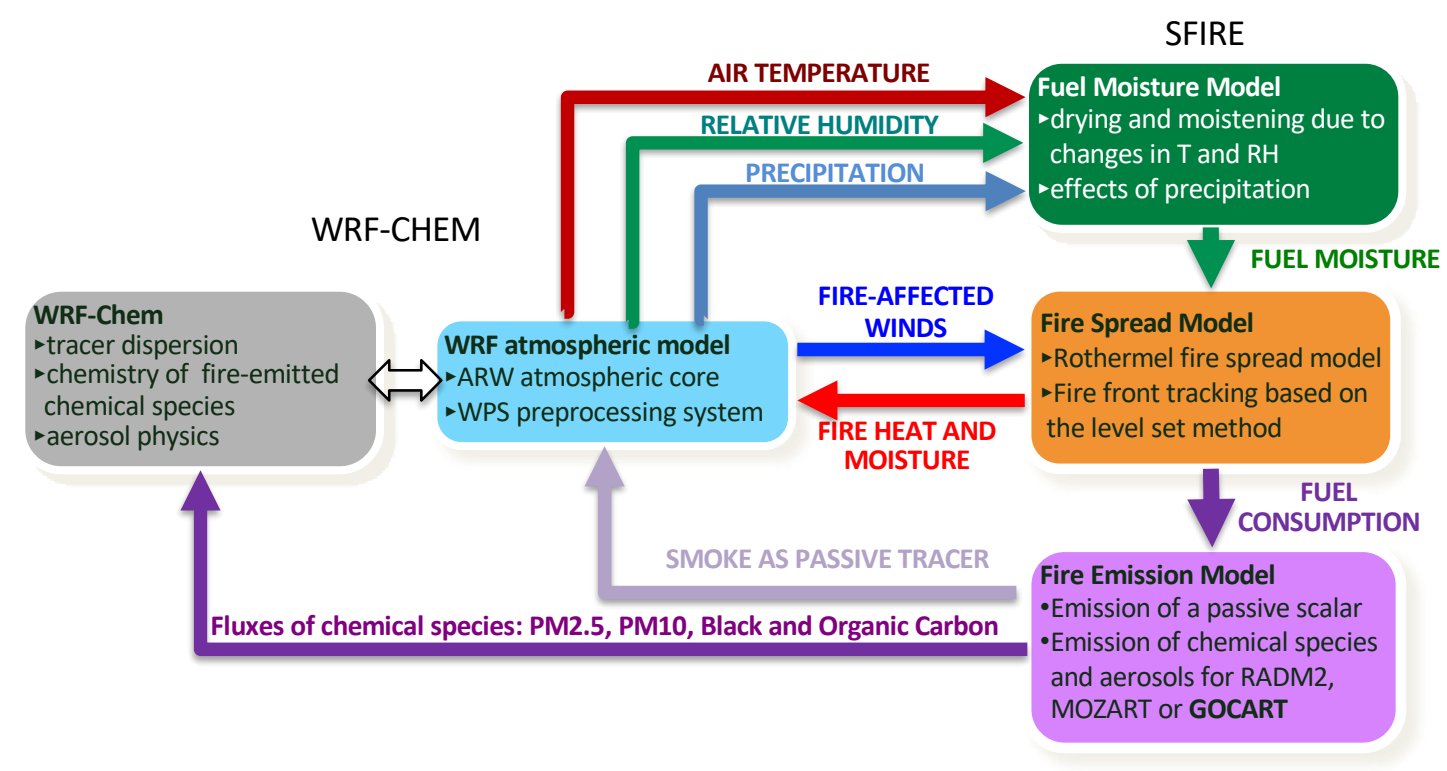

Figure 2 - Diagram of the WRF-SFIRE-CHEM model.

WRF-SFIRE-CHEM has been configured with three nested domains with horizontal resolutions of $12 \mathrm{~km}, 4 \mathrm{~km}$, and $1.33 \mathrm{~km}$, respectively. A total of 6 fires were simulated, with 5 of them being located within the innermost domain $\mathrm{d} 03$ and one within domain d02 (see Figure b). The simulation was initialized on August $16^{\text {th }} 0000$ UTC and ran for seven days, with boundary conditions being derived from the Climate Forecast System Reanalysis (CFSR) data (Saha et al. 2014). The fire model was executed on a 1:20 refined mesh, with the horizontal resolution of $67 \mathrm{~m}$. The fuel description came from the LANDFIRE dataset available at https://www.landfire.gov/.

Two numerical simulations were carried out in order to quantify the impacts of smoke on surface temperatures across northern California. The first one was defined as the "baseline simulation", where WRF-SFIRE was ran with no radiative smoke impacts. The second model configuration used WRFSFIRE-CHEM, where smoke emissions computed from fuel consumption were linked to the GOCART aerosol scheme, which interacts with the atmospheric radiation scheme. As a result, this WRF-SFIRE-CHEM configuration is able to account for the impacts of smoke aerosols on incoming 
solar radiation. Both model simulations had fire growth prescribed using the fire arrival time derived as a spatial interpolation between observed fire perimeters. An example of the encoded fire progression is shown in Figure .

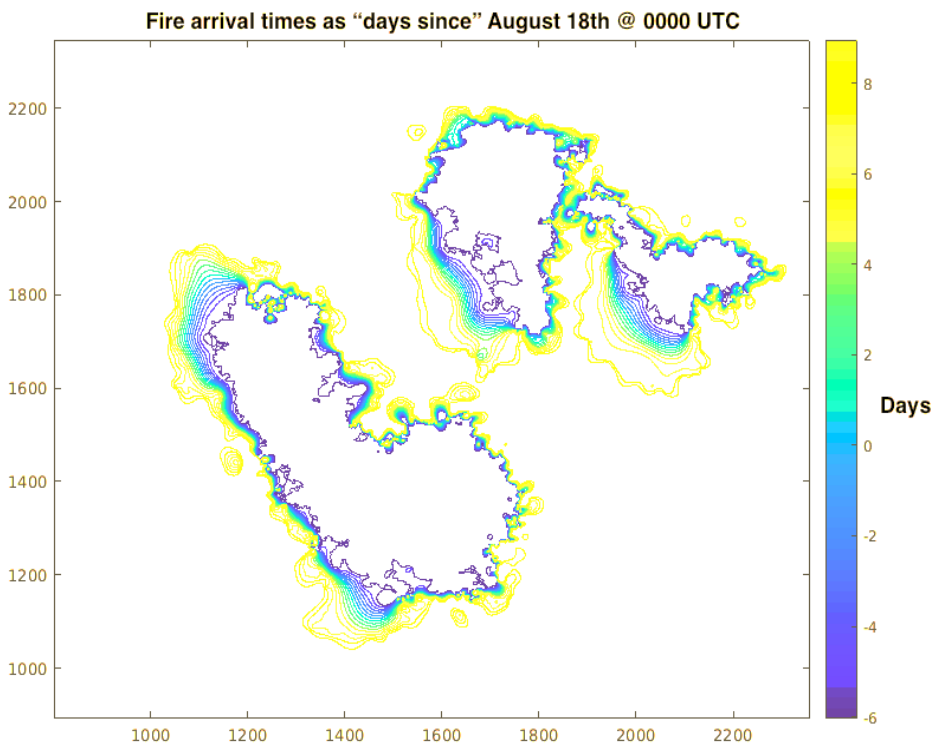

Figure 3 - An example of the fire arrival time derived from observed fire perimeters for the Route and South Complex fires.

\section{Results}

Temperature and incoming solar radiation from both WRF-SFIRE model configurations were compared to observations at two stations that were adjacent to the River Complex and South Complex fires. The first station (Big Bar; BGBC1) was located within the Trinity River valley, with an elevation of 524-m, while the second site was located at the top of the Trinity River valley and had an elevation of 1005-m (Trinity Camp - TCAC1). The elevation map of the innermost model domain and the location of these two stations are shown in Figure.

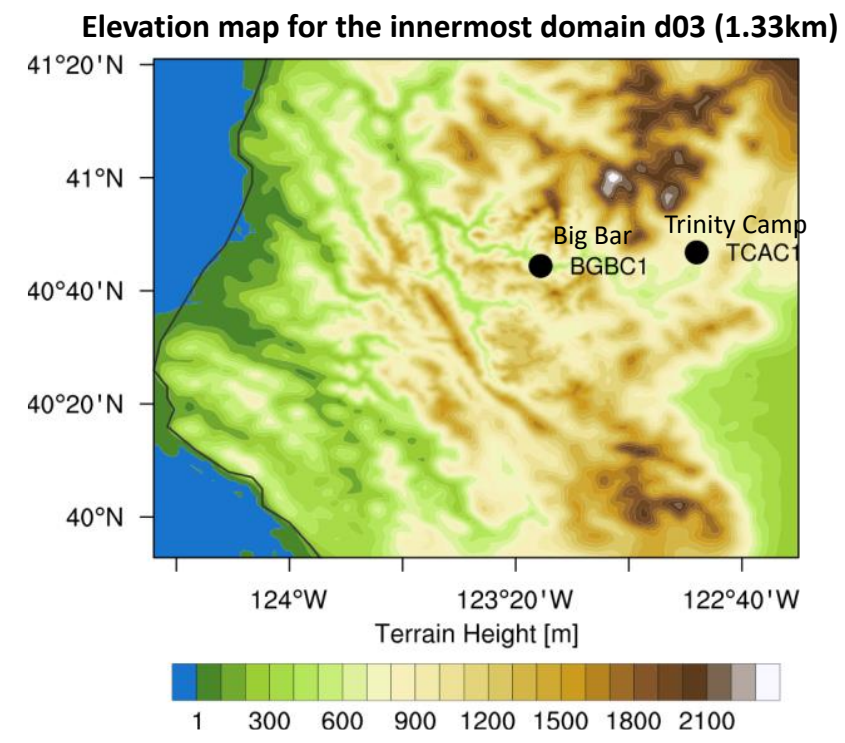

Figure 4 - Elevation map of the innermost domain 103 and the location of measurement stations used in the analysis 
Observational data from these stations indicated that the Big Bar station, located deeper in the valley, observed a more significant reduction in the incoming solar radiation, than the Trinity Camp, located higher in the mountains. It was hypothesized, that these differences were a consequence of each site's geographic location resulting in different aerosol optical depths in the smoke layers above each site. Model simulations performed with, and without the radiative impact of smoke confirmed that the observed deficit in the incoming solar radiation was associated with the presence of the smoke layer.

The time series of the simulated and observed incoming solar radiation at these two stations presented in Figure illustrate that during the first three days when the stations were mostly smokefree, the simulations with and without radiative impacts of smoke showed very similar results. However, at the end of August 19 ${ }^{\text {th }}$, and the beginning of August $20^{\text {th }}$, (Figure ), a dramatic decrease in the incoming solar radiation was observed at the Big Bar station in the WRF-SFIRE-CHEM run accounting for the radiative impact of smoke. The Trinity Camp also experiences a decrease in the insolation but not as significant as the Big Bar.

These results suggest that the smoke covering the Trinity River Valley could have been a reason for the observed discrepancies between the Big Bar station located deeper in the valley and consequently covered by a thick layer of smoke, versus the Trinity Camp station, located higher and covered by a shallower smoke layer.

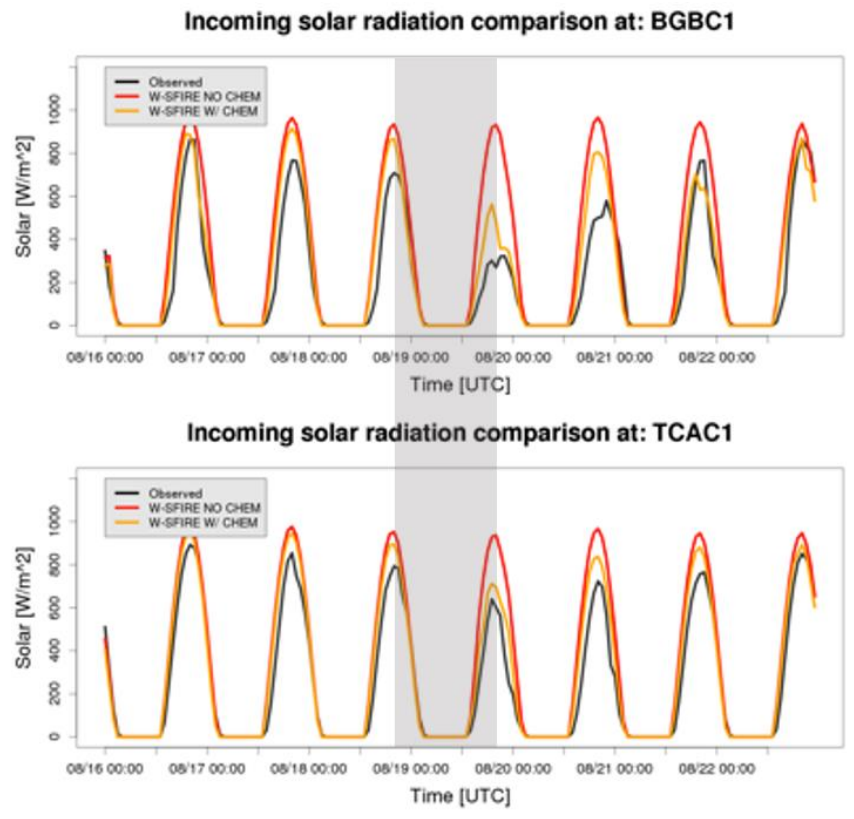

Figure 5 - Time series of the simulated and observed incoming solar radiation at the Big Bar station (BGBC1) - top panel, and the Trinity Camp station (TCAC1) - bottom panel. Observed temperatures plotted as the black line, the baseline simulation is plotted in the red line, and the orange line represents the WRF-SFIRE simulation with aerosol impacts. Gray shading denotes period where smoke-inversion conditions were present.

The impact of the fire smoke is also evident in the $2 \mathrm{~m}$ air temperature time series presented in Figure . Prior to the smoke inversion conditions on the 19 and $20^{\text {th }}$ of August, the simulations with and without radiative impacts of smoke are nearly identical. However, on August $19^{\text {th }}$ and $20^{\text {th }}$ the temperatures for these simulations diverge. The simulation accounting for the smoke shading showed a temperature that was $3^{\circ} \mathrm{C}$ cooler at Big Bar relative to the baseline run. The timeseries for the Trinity Camp station also showed some cooling due to the smoke, but as expected, it was not as pronounced as the cooling at the Big Bar, which is located deeper in the valley. Model comparisons across northern California on August $19^{\text {th }}$ at 2100 UTC indicates that much of the area was infiltrated by smokeemitted $\mathrm{PM}_{2.5}$, with concentrations exceeding $100 \mu \mathrm{g} \mathrm{m}^{-3}$ (Figure a). 


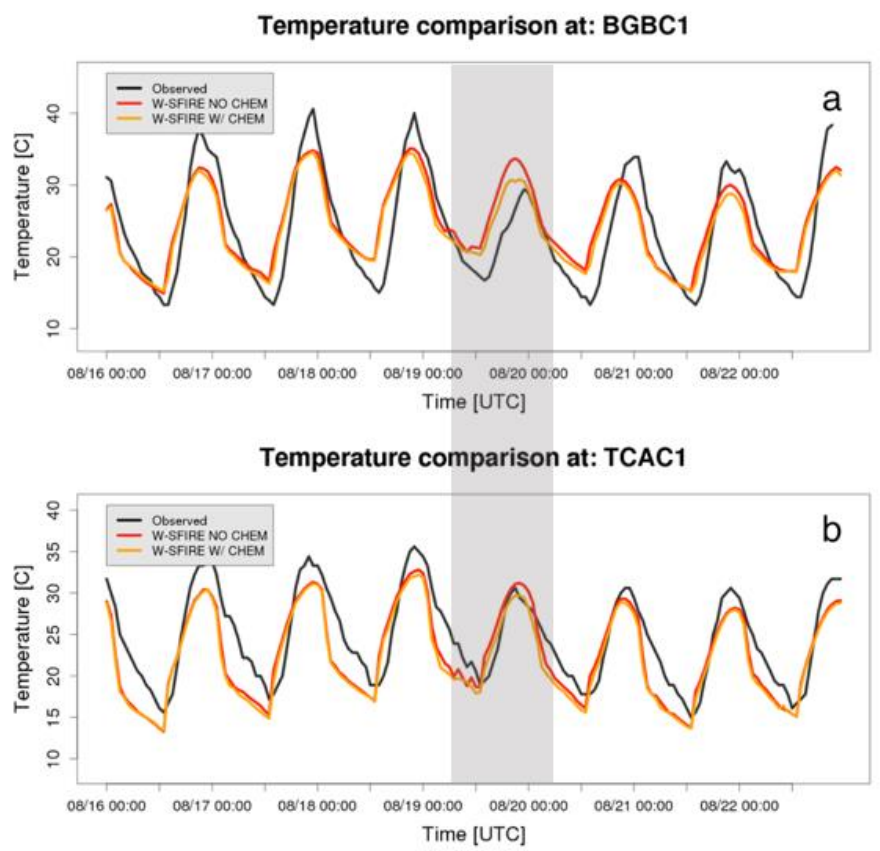

Figure 7 - Same as Figure 5, but for 2-m temperature..

Incoming solar was significantly reduced in the WRF-SFIRE simulation that included aerosol impacts, which saw deceases approaching $600 \mathrm{Wm}^{-2}$ at some locations (Figure b). Similar decreases were also seen in 2-m temperatures, which were mostly confined to river valleys across northern California (Figure c). Finally, wind speed decreases were also observed across the study region (Figure d), which was likely the result of smoke-induced inversions decoupling surface winds from the free troposphere.
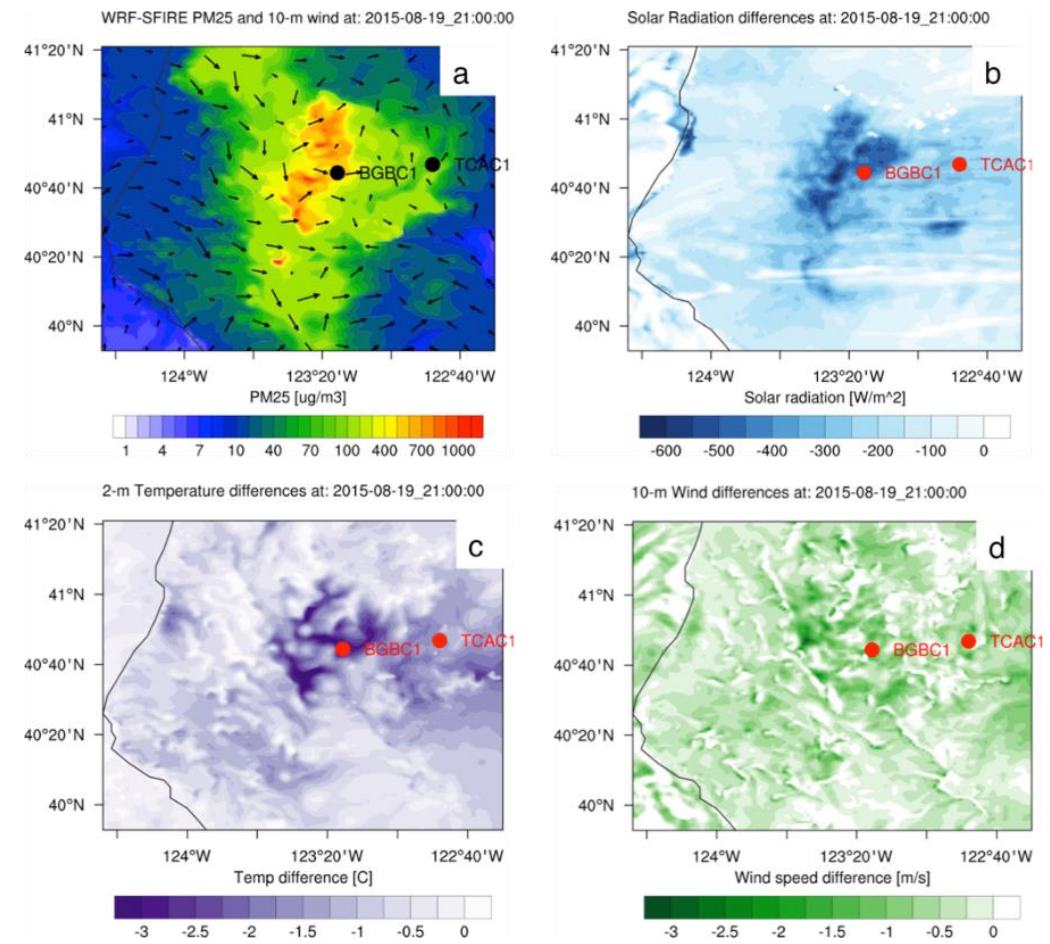

Figure 7 - (a) Modeled PM2.5 concentrations and 10-m winds, differences between the WRF-SFIRE configuration that included aerosol impacts and the baseline simulations for (b) solar radiation, (c) 2-m temperature differences, and (d) wind speed. Panels are for August $19^{\text {th }}, 2015$ at 2100 UTC. 
The visible correlation between the patterns of $\mathrm{PM}_{2.5}$ concentration, radiation reduction, and surface cooling indicates that the observed dampening of the diurnal temperature cycle at the Big Bar station was related to the local impacts of the fire smoke that strengthened inversions by decreasing incoming solar radiation and surface temperatures.

In order to assess the fire impact on the thermal structure of the atmosphere, the vertical temperature profiles over the Trinity Valley was analyzed. The comparison between the baseline simulation and the pure atmospheric run without fire didn't reveal any measurable differences in the temperature profiles. This suggests that in the case of low-intensity fires, the direct thermal effect of the fire is negligible and didn't significantly contribute to the observed inversions. However, the differences between the baseline simulation and the WRF-SFIRE-CHEM run indicate that smoke layer had a significant impact on the thermal structure of the atmosphere (Figure ). The presence of the smoke layer has a dual effect. The smoke shading, (radiation blocking) results in surface cooling, while the absorption of radiation at higher elevations results in slight warming. This double effect tends to stabilize the atmosphere and promote persistent smoke-enhanced inversions.

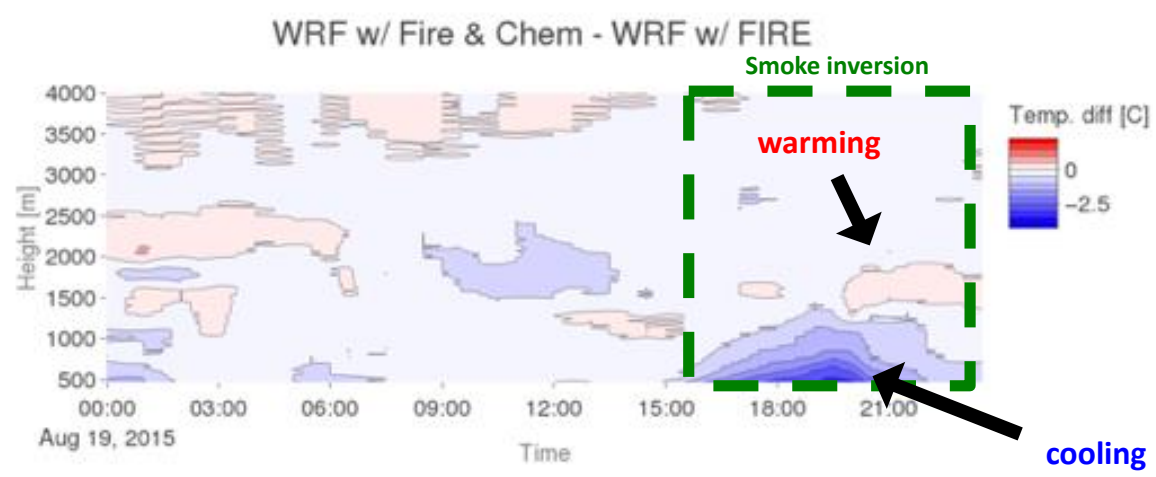

Figure 8 - Difference between the temperature from the baseline WRF-SFIRE run and the WRF-SFIRE-CHEM run with radiatively active smoke, showing time evolution of the vertical temperature modification due to the smoke.

\section{Conclusions}

Preliminary results indicate that local weather modifications due to the wildfire smoke are significant enough to motivate the inclusion of fire smoke impacts on local weather conditions within the numerical models. In the analyzed case the wildfire smoke reduced incoming solar radiation by up to $600 \mathrm{~W} / \mathrm{m}^{2}$, which lead to local surface cooling reaching $3^{\circ} \mathrm{C}$. This work suggests that the inclusion of fire-smoke-atmosphere feedbacks in a coupled modeling framework such as WRF-SFIRE-CHEM may help capture the impacts of wildfire smoke on near-surface stability and local inversions. Furthermore, results here suggest that smoke may have impacts beyond increasing atmospheric stability and decreasing temperatures in smoke infiltrated valleys. The smoke-enhanced inversions tend to inhibit the vertical mixing and consequently reduce near-surface winds. This interaction generates positive feedback, in a sense that the smoke layer cools down the surface, stabilizes the atmosphere, and reduces surface winds which in turn limits the smoke ventilation and promote persistent inversions. Also, as the smoke-induced inversions inhibit the surface flow, the inversion break-ups, or the upslope fire propagation protruding through the inversion layer may lead to significant fire acceleration.

\section{Acknowledgements}

This research was sponsored by the USDA grant 16-CS-11132543-075. The authors would also like to acknowledge the support of the National Science Foundation grants DMS-1216481, ICER1664175, the NASA grant NNX13AH59G to Colorado State University, Sher Schranz, PI, CIRA in 
affiliation with NOAA/ESRL, as well as the JFSP grant 15-1-02-2 to the Washington State University. The authors would like to acknowledge high-performance computing support from Cheyenne (doi:10.5065/D6RX99HX) provided by NCAR's Computational and Information Systems Laboratory, sponsored by the National Science Foundation. The computing support from the University of Utah Center for High Performance Computing is greatly appreciated.

\section{References}

Albini, F. A., 1982: Response of free-burning fires to nonsteady wind. Combustion Science and Technology, 29(3-6), 225-241.

Andrews, Patricia L. 2009. BehavePlus fire modeling system, version 5.0: General Technical Report RMRS-GTR-213WWW. Revised. Fort Collins, CO: U.S. Department of Agriculture, Forest Service, Rocky Mountain Research Station. 111 p.

Chin, M., R. B. Rood, S.-J. Lin, J. F. Muller, and A. M. Thomspon, Atmosphericsulfur cycle in the global model GOCART: Model description and global properties, J. Geophys. Res., 105, 24,67124,687, 2000.

Clements, C.B., Perna, R., Jang, M., Lee, D., Patel, M., Street, S., Zhong, S., Goodrick, S., Li, J., Potter, B.E. and Bian, X., 2007: Observing the dynamics of wildland grass fires: Fireflux - a field validation experiment. Bull. Amer. Meteor. Soc., 88,1369-1382.

Forthofer, J.M., Butler, B.W., and N.S. Wagenbrenner, 2014a: A comparison of three approaches for simulating fine-scale winds in support of wildland fire management: Part I. Model formulation and accuracy. Int. J. Wildland Fire, 23, 969-981.

Grell, G., and A. Baklanov, 2011: Integrated modeling for forecasting weather and air quality: a call for fully coupled approaches. Atmos. Environ., 45, 6845-6851.

Kochanski, A. K., M. A. Jenkins, K. Yedinak, J. Mandel, J. Beezley, and B. Lamb, 2016: Toward an integrated system for fire, smoke, and air quality simulations. Int. J. Wildland Fire 25, 558-568. doi:10.1071/WF14074

Lareau, N.P., and C. B. Clements, 2015: Cold Smoke: smoke-induced density currents cause unexpected smoke transport near large wildfires. Atmos. Chem. Phys., 15, 11513-11520.

Lareau, N.P., and C. B. Clements, 2017: The mean and turbulent properties of a wildfire convective plume. J. Appl. Meteorol. and Climatol., 56, 2289-2299.

Mandel, J., S. Amram, J. D. Beezley, G. Kelman, A. K. Kochanski, V. Y. Kondratenko, B. H. Lynn, B. Regev, and M. Vejmelka, 2014: Recent advances and applications of WRF-SFIRE. Natural Hazards and Earth System Sciences, 14, 2829.

Saha, Suranjana, and Coauthors, 2014: The NCEP Climate Forecast System Version 2. J. Climate, 27, 2185-2208 